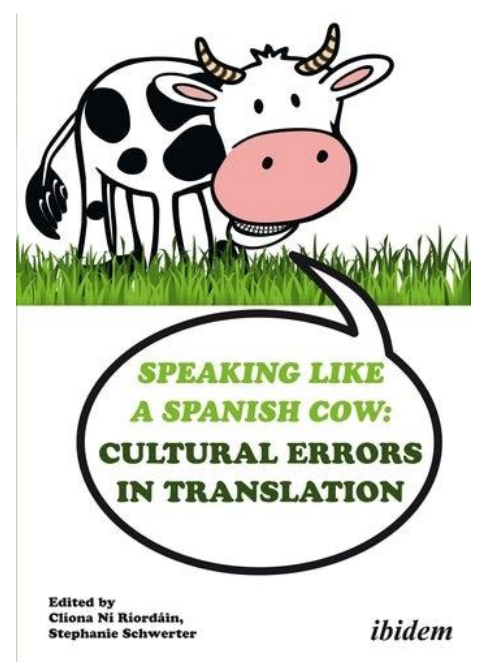

\title{
Ní Ríordáin, Clíona and Stephanie Schwerter. Speaking like a Spanish Cow: Cultural Errors in Translation. ibidem-Verlag, 2019. 372 pp.
}

\section{Laura L. Velazquez University of Alberta}

The editors present fifteen essays by eighteen contributors. In their introduction, Clíona Ní Ríordáin and Stephanie Schwerter draw attention to two problems: theoretical work exclusively devoted to analyze the notion of cultural errors is inexistent; and the notion of cultural error, especially when used for didactic purposes, is often studied from a purely linguistic perspective. The result of the first predicament is the present volume. The editors bring together a group of scholars, from different linguistic backgrounds, working in fields as varied as art, tourism, literature, popular culture and in languages and cultures such as English, French, German, Modern Greek, Persian, Russian and Spanish. They address the second problem by suggesting a broader understanding of cultural error, one that draws upon Mary Louise Pratt's notion of "contact zone," a space of cultural struggle where power is negotiated. From this perspective, cultural errors can take the form of loss, manipulation, misreading or creative impulse (xviii). These same categories serve as headings for each of the three sections of the book.

The volume begins with a chapter entitled "Errors or Manipulation?" This segment incorporates essays reflecting on ambiguous instances in which it is not clear whether an omission or faulty translation is the product of the translator's deliberate preference, negligence or misunderstanding. An example of such dichotomy lies at the heart of Katja Grupp's detailed analysis of the cultural errors of translations included in the Russian website https://inosmi.ru/, an online space dedicated to translating into Russian articles about Russia by western journalists. In other words, the site is a 
compendium of news about Russia as seen through the eyes of others. The puzzling nature of the website is explained by the "Russians' lack of self-confidence in the wake of the fall of the Soviet Union" (24). A common denominator of many of the translations that get published on the website is that they are plagued with cultural errors ranging from flagrant omissions to more subtle manipulations, some of them motivated by the interference of unconscious tracks of thought (Freudian slips). While the chapter suggests that cultural errors made by the Russian translators are ideologically driven and their function is to manipulate public opinion, as well as to influence foreign policy (23), it would be interesting to delve more deeply into the topic to explore other kinds of urges (to keep with the Freudian theme) that these "unintentional" errors might account for.

In the second part of the volume, "(Mis-) reading cultural references," the editors include several works that deal with cultural errors produced either by the translator's "insufficient knowledge" of the source language and culture, or by plain misunderstanding. In their richly informative study of cultural errors in tourist texts, Ana Isabel Foulquié-Rubio and Paula Cifuentes-Férez establish the pivotal role of translation for the tourism industry. First, they argue, translation should be used as a medium to enrich tourists' experience and offer them something they can relate to (language in this case) in an otherwise foreign and unfamiliar place; and second, "translation must be considered as a tool for mediating between different cultures" (209). The difficulties behind this process of mediation are not to be underestimated. The translation of culturally specific terms (culturemes), for instance, is a challenge that not every translator can successfully address and ultimately resolve. The complexity of the endeavour increases in the case of tourist texts requiring the use of a common language to be understood by people from different cultural backgrounds. A highlight of this essay is its didacticism. Not only do Cifuentes-Férez and Foulquié-Rubio examine in detail various examples of cultural errors, particularly from the gastronomical field, but also propose ways to solve the difficulties posited by them. Professional translators, without a doubt, can benefit from their suggestions.

"Creative errors" is the topic of the third and last section of the book. In this part, the reader will find contributions focused on examining cultural errors as a sort of happy coincidences that prompt creativity. Jean Charles Meunier contributes to this topic with a fascinating analysis of the cultural errors in two French translations (or adaptations?) of Bob Dylan's narrative song "Motorpsycho nitemare." The author thoroughly unfolds the intertextual cultural references of the song and points out the difficulties of translating such material: humor too culturally specific, the rhythm of the song (talking blues) and the use of parody. Meunier is categorical in his assessment of the French translations: they do not completely transmit the essence of Bob Dylan's song. Omissions, failed domestications, and performative inaccuracies are some of the errors made by the translators/performers. While throughout the chapter it is clear that the resulting French songs are translations, the author suggestively states at the end that whether the choices made by the French translators/performers should be considered creative licenses of an adaptation is open to debate. But, if that is the case, and translation of cultural products can be considered a creative process itself (as it is in adaptation), shouldn't we be more open to the products of unfaithfulness? 
One of the strengths of this volume is its disciplinary and linguistic variety, and paradoxically, the latter is also one of its weaknesses. It was pleasantly surprising to read in the collection studies on peripheral cultures and languages, such as Persian, but it was equally disheartening to find a lack of representation of Asian languages, which would have made exceptional study cases of cultural errors. This of course, in no way, diminishes the contribution that the volume offers in the field of translation studies. Comparatists and cross-cultural studies enthusiasts, like myself, will also find the book especially relevant in an academic world where the death of comparative literature has been predicted more than once. While books like this one do not deny the prophecy, they do show that perhaps the discipline is not doomed to disappear but is making a return in a different form. 